\title{
Aquele que Penteia Cometas e Condensações
}

Resumo

Trata-se da tradução para o português de Prefácio e Posfácio ao Libreto do Macbeth de Shakespeare segundo Carmelo Bene, publicado na França.

Palavras-chave: Carmelo Bene - Macbeth Shakespeare - atorialidade

\author{
Abstract \\ The text presents the Portuguese translation of \\ the preface and postface of the Libretto of Shake- \\ speare's Macbeth according to Carmelo Bene, \\ published in France. \\ keywords: Carmelo Bene - Macbeth - Shake- \\ speare - actoriality
}

\footnotetext{
* Professor emérito de Literatura Italiana Contemporânea da Universidade de Lille III, é ensaísta, tradutor e romancista. Traduziu as Obras Completas de Carmelo Bene para o francês e é responsável por importantes ensaios sobre o artista italiano

** Doutora pelo Núcleo de Estudos da Subjetividade da PUC-SP, é professora do Programa de Pós-Graduação em Artes Cênicas e do Departamento de Arte Dramática da Universidade Federal do Rio Grande do Sul e pesquisadora da obra de Carmelo Bene.

E-mail: silvia@bnunes.com.br
} 


\section{Apresentação}

Silvia Balestreri

Uma das características da semovente obra do italiano Carmelo Bene (1937-2002) é a re(o)corrência de algumas criações em diferentes momentos ou em distintos meios - teatro, rádio, cinema, disco. No caso de um mesmo meio, como o teatro, nas obras completas do artista, publicadas com ele ainda em vida, e em listas de importantes estudiosos de sua arte ${ }^{1}$, são denominadas "edições" as diferentes montagens emanadas de um mesmo texto originário. Bene fez várias incursões em Shakespeare, dentre as quais, duas edições para o teatro e uma obra televisiva de Macbeth, a saber, respectivamente: Macbeth, due tempi di Carmelo Bene da Shakespeare, que estreou no Teatro Lírico de Milão em janeiro de 1983 e foi apresentada no mesmo ano em Paris; Macbeth Horror Suite ( $2^{\mathrm{a}}$ edição), "de Carmelo Bene, a partir de William Shakespeare, no centenário do nascimento de Antonin Artaud”, que estreou em setembro/outubro de 1996, no Teatro Argentina, em Roma, e, duas semanas depois, foi também apresentada em Paris, no Teatro Odeon, dentro da programação do Festival de Outono; e uma versão televisiva de Macbeth Horror Suite, realizada em 1996, e transmitida pela emissora de TV Rai Due em abril de $1997^{23}$.

Os textos aqui traduzidos fizeram parte de uma pequena publicação chamada "libreto" do Macbeth de Bene, editada por Dramaturgie. Esta, mais que uma editora, era o que hoje chamaríamos um "coletivo", do qual participavam Manganaro e outros intelectuais, e que divulgou, na França, nos anos 1970, a obra de vários artistas italianos, dentre os quais, Bene e Dario Fo. Sob responsabilidade de Manganaro, promoveu uma das primeiras apresentações de Bene em Paris e sua aproximação a intelectuais como Gilles Deleuze e Pierre Klossovski.

Nos textos a seguir, as citações do próprio Bene sobre Macbeth foram retiradas por Manganaro de suas obras completas, de 1995, escritas, portanto, antes da montagem teatral e da produção televisiva de Macbeth Horror Suite. Os textos "beneanos" das versões de Macbeth, infelizmente não publicados aqui, são retirados, tais e quais, do texto de Shakespeare, com os cortes "cirúrgicos", como destacou Gilles Deleuze, que o artista costumava fazer e, no caso, com muitas inserções da ópera Macbeth de Giuseppe Verdi, cujo libreto é de Francesco Maria Piave. Submetida a uma disputa judicial entre os herdeiros, as obras do próprio Bene não são facilmente autorizadas para publicação, daí a importância do acesso em português a textos de um dos seus mais importantes estudiosos. Como diz Carmelo Bene, "Macbethizemos"!

\section{Aquele que Penteia Cometas ${ }^{45}$}

Jean-Paul Manganaro Tradução: Silvia Balestreri

No final dos anos 70, o jornal L’Espresso, fazendo um balanço de uma “década italiana", recomendava que se fosse assistir a Carmelo Bene no teatro a mesmo título que se visitasse o Coliseu. Se ele era já monumental àquela época, após haver recebido outras denominações como as de menino mimado ou de monstro sagrado do teatro italiano, a publicação de suas Obras Completas vinte anos mais tarde, em 1995, na coleção dos grandes clássicos do editor Bompiani, coroou um trabalho e um destino singulares.

Após haver abandonado a "Accademia"6 - onde um de seus professores, o conde de Liguore, destacava as entonações únicas de sua voz e sublinhava suas colorações, pedindo-lhe, por exemplo, o que ele ia "cantar

\footnotetext{
l Ver BENE, Carmelo. Spetacoli. In:__. Opere. Milão: Bompiani, 1995. 1556-1560. E também GIACCHE, Piergiorgio. Gli spettacoli di Carmelo Bene - Teatro. In:__. Carmelo Bene: antropologia di unaa macchina attoriale. 2. ed. Milão: Bompiani, 2007 [1997]. 206-212.

2 Informações colhidas em Giacchèe, op. Cit, e em BENE, Carmelo. Théâtre - Oeuvres complètes II. Tradução e organização de Jean-Paul Manganaro. Paris: P.O.L., 2004.

Versão televisiva disponível em https://www.youtube.com/watch?v=i7fj9AMVQD4, acesso em dezembro de 2014.

MANGANARO, Jean-Paul Le léger peigneur de comètes. In : BENE, Carmelo. Macbeth : livret en 13 mouvements de Carmelo Bene d'après Shakespeare. Paris : Dramaturgie-José Guinot, 1996. 7-10. Prefácio.

5 melo Bene dapres Shakespeare. Paris : Dramaturgie-Jose Guinot, 1996. 7-10. Prefácio. peigneur de comêtes!" Foram consideradas, aqui, as opções de tradução sugeridas por Marcos Antônio Siscar, em CORBIERE, Tristan. Os amores amarelos. São Paulo: Iluminuras, 1996. Uma tradução mais literal seria "O Ágil Cardador de Cometas" [N.T.] 
hoje” -, Carmelo Bene nasce para a cena em Calígula, de Camus. Sua interpretação é imediatamente destacada pelo conjunto da crítica italiana naquilo que evoca "o mal estar de uma grandeza escandalosa" e uma "alma angustiada e pura no mal”. Se há algo de verdade nesses julgamentos, é também verdadeiro que por muito tempo nutriram uma imagem e uma ideia particulares de seu teatro, mas ocultaram um dado seu mais significativo, fundado sobre a polêmica constantemente alimentada por Carmelo Bene com respeito à representação e mesmo à espetacularização.

A partir dos anos 60, ele começa um trabalho frenético nas cantinas de Roma, com duas ou três performances anuais e interpretações que se constituem como pontos nevrálgicos: Pinocchio e Maiakovski são os momentos fortes, através de retomadas e reelaborações marcantes, trabalhados como símbolos de uma constituição progressiva de um ego do personagem teatral e do ator - da ingenuidade aparente da marionete ao poeta suicidado da sociedade. A essas duas figuras tornadas míticas virá rapidamente se juntar um longo trabalho sobre Hamlet: se sua matriz é essencialmente o modelo shakespeareano, sua apresentação, por outro lado, é constantemente "esgotada e minorada" - como sublinha Gilles Deleuze - para uma linguagem mais irônica inspirada no poeta Jules Laforgue, ao qual Bene acrescenta, em surdina, textos de Freud teatralizados e outras tantas passagens humorísticas.

É, aliás, com Um Hamlet a Menos, que se conclui, em 1972, a experimentação cinematográfica de Bene, breve e flamejante, cujos começos foram marcados pela realização de Nossa Senhora dos Turcos, que recebeu, em 1968, após mil polêmicas, o prêmio da Mostra de Veneza, dividido com Robert Lapoujade. Os outros momentos singulares desse percurso são os filmes Don Juan e Capricci, cuja inspiração remete a certas figuras da cultura francesa. O gosto pela "velocidade" que Bene manifesta no momento da montagem de seus filmes, as colorações e os cortes tomados emprestados de seu próprio cinema serão outras tantas experiências fortes para a constituição de seu teatro.

A partir de 1974, o essencial de seu trabalho se concentra sobre algumas obras de Shakespeare reelaboradas por ele em uma dimensão que põe em jogo múltiplos: para Bene, a questão não é mais representar pela enésima vez os grandes momentos filológicos das obras, mas, guardando seu élan e seus maiores valores, extrair delas seus ocos e vazios, habitáveis apenas por um ator atravessado por experiências que se distinguem dos repetecos mais ou menos significativos de uma linguagem escrita - aqui pensamos mais precisamente nos questionamentos e reestruturações desejados e inaugurados por Artaud. Neste sentido, o trabalho de Bene se constitui como um grande momento de "desprovincialização" do teatro italiano e europeu no seu conjunto e como um momento de grande criação poética. As situações - e não mais os papéis - escolhidos dentro do repertório, a saber Hamlet, Ricardo III, Otelo, Macbeth, não cessam de, polemicamente, colocar em discussão e em crise as funções e as relações que reúnem os diversos "actantes" do espetáculo, e sobretudo a presença do ator em cena, percebido em sua relação de "inutilidade” tanto em relação ao texto quanto à representação. Daí surge uma nova função cênica chamada por Bene de "função atorial" ou "atorialidade", que não mais se encarrega de uma temática e de uma presença em cena obsoletas, mas uma liberdade que permite ao ator se investir na multiplicidade de suas potências criativas.

Como pode ainda o ator se representar em cena? Como liberar o teatro e o ator do esmaecimento ocasionado pela estratificação das formas sucessivas de representação fictícia da realidade e do real que se acumularam e que os reduziram a uma reprodução constante através das épocas, mesmo se os modos levam a crer que as formas mudaram. São questões às quais, em outros domínios, da literatura à pintura e ao cinema, a criação tentou trazer respostas determinantes, sem transcender as questões, mantendo em vista a imanência das situações. Eis talvez o essencial da questão que coloca Bene e à qual ele responde com um longo trabalho, praticamente sozinho desde o início dos anos 6o. Contra todo um teatro de filologias - notadamente, em oposição radical com a teatralização de Strehler -, trata-se de reinventar as funções poéticas que permitam ao "artifex" 7 teatral ser "aquele que penteia cometas" imaginado por Tristan Corbière ${ }^{8}$. Nestes últimos tempos, desde seu belíssimo Lorenzaccio em 1987, o teatro de Carmelo Bene soube mais uma vez se transformar: de multicolorido que era, tornou-se preto e branco, estriado de prata, evocando uma grande e alta solidão de alguns restos ilusórios e alucinatórios do teatro: só em seu teatro e em seu cantar, como o pintor está só, não diante da tela, mas em sua pintura. 


\section{Condensações 9}

Jean-Paul Manganaro Tradução: Silvia Balestreri

A transcrição que Carmelo Bene faz de Macbeth data de 1982 e constitui, até o momento, o último domínio de uma série de reelaborações shakespeareanas que lhe permitiram revisitar sucessivamente Hamlet, Romeu e Julieta, Ricardo III e Otelo. Muitas revisitações cujo objetivo não é certamente magnificar um dos mais altos lugares da dramaturgia ocidental, nem de propor-lhe uma releitura moderna. São os topoi específicos de moralidades tornadas lendárias à força de terem sabido envelhecer e captar múltiplas essências humanistas cujo espectro de refração e de ressonância é muito grande. Eis, talvez, o ponto de vista que escolhe Carmelo Bene: cada uma de suas obras delimita uma só situação particular à qual ele não tem nada a acrescentar.

A bem dizer, há muitas coisas a retirar, a subtrair: basta reler em Superpositions o que Deleuze ${ }^{10}$ expli- $^{-}$ cou perfeitamente desta operação constante de subtração em Bene, para se dar conta de sua necessidade. Uma necessidade mesmo histórica, isto é, concernente à história da peça ou à história do teatro, para além, portanto, ou aquém, de uma poética própria à Carmelo Bene.

Assim, não é um problema de texto, de contexto ou de pretexto: essa questão, com Bene, não tem mais sentido, ou, ainda, ela tem um sentido relativo, um sentido de fundo - como se diria do fundo de um quadro, da descrição da paisagem em um romance, que de repente se imporia acima do resto - de tal modo distante, que apenas lhe prestamos uma atenção distraída, na qual ela mesma se inscreve, na qual ela é desejada e mantida. Aquilo que se descreve, aquilo que se desenha nos últimos trabalhos do "não-ser ao teatro" de Carmelo Bene é justamente a crítica dessa relação que nós mantemos com as obras ditas de repertório. Macbeth, Hamlet, Ricardo III ou Lorenzaccio não representam mais heróis ou anti-heróis, nem mesmo situações, mas lugares comuns que se revisita em pontos sublinhados por uma cultura do "momento poético", cuja tradição é doravante débil. Esses lugares comuns são conhecidos: as bruxas, as visões, o sangue; o fantasma do pai, a problemática ontológica do Príncipe de Elseneur, seu antifeminismo gnóstico; a corcunda disforme de Ricardo III e seu cavalo; tantos clichês produzidos por essas peças proverbiais. Ora, nós não paramos de adicioná-los, de acumulá-los, de propagá-los ao irmos ao museu-teatro e de reencontrá-los ritualmente, para bem verificar e controlar, em uma plenitude complacente e narcísica, que gestos e palavras estão sempre ali tais e quais e que eles resistem a toda sorte de intempéries e de ultrajes - quer dizer, resistem a toda época, a toda ideologia, a toda encenação, a todo jogo de ator.

Em alguns textos escritos em momentos diferentes, Carmelo Bene explicitou aquilo que ele escuta em Macbeth $^{11}$. O primeiro cronologicamente desses textos sublinha, no tom de um humor sarcástico, motivos que poderiam parecer secretos na obra, ou na leitura histórica que se fez dela. O ponto de partida é uma comparação com Ricardo III. Macbeth e Ricardo III, diz Bene, divergem sobre dois fatos essenciais: enquanto Ricardo é solteiro, Macbeth é casado; mas "o privilégio da cópula conjugal” não nos deve enganar, porque, nas duas histórias, a verdadeira Lady, a Lady soberana é a "masturbação", da qual, no fundo, "a cópula conjugal dos reis da Escócia é apenas um substituto". E ele acrescenta uma ideia essencial para a compreensão dos mecanismos: "Todo lar que se respeita é feito de cumplicidades, não quanto à decoração da casa ou sobre quem vai fazer as compras. De fato, a cumplicidade levada a seu apogeu é a realização de um delito, e disso decorre que todo crime é uma história de amor."

Como era já o caso para Romeu e Julieta, Carmelo Bene ama imaginar um Shakespeare em estado de sonolência, um estado mais de abandono e de embriaguez que de transe, que se refletiria sobre seus personagens: "Macbethizemos. Duncan-corpo histórico, sonolência real, se deixa estremecer, uma bela manhã, pelo cocorico da quietude universal dos vivos, isto é, os não-mortos definitivos. Ai!, lhe acontece de fazer um gesto insensato: ele desfaz imprudentemente os curativos de sua imobilidade diante da ama-de-leite do 'agir-padecer' que o precipita em Macbeth (sua própria morte, pra começar) e, como ator demencial, ele persegue a vida e, na vida, ele é belo e bem casado com um digno amor (digno amor de teatro): sua mulher-menino-Lady

\footnotetext{
9 MANGANARO, Jean-Paul. Condensations. In : BENE, Carmelo. Macbeth : livret en 13 mouvements de Carmelo Bene d'après Shakespeare. Paris : Dramaturgie-José Guinot, 1996. 43-49. Posfócio.

10 Carmelo Bene/Gilles Deleuze, Superpositions, Ed. Minuit, Paris, 1979. [N.T.: No Brasil, apenas o texto de Deleuze que compõe esta obra foi publicado junto a outro texto seu sobre Beckett, em DELEUZE, Gilles. Sobre o teatro: Um manifesto de menos; O esgotado. Rio de Janeiro: Zahar, 2010.]

11 Todas as citações entre aspas foram tiradas de diferentes prefácios que Carmelo Bene escreveu sobre seus Macbeth sucessivos, in Opere, Ed. Bompiani, Milão, 1995.
} 
Macbeth. E - tanto o vento leva ${ }^{12}$ - eles se amam do sangue que se assenta ao amor que se diz. Ambos trazem danos a seu amor (o corpo real de Duncan é apenas um simulacro), excitando-se sucessivamente em demasia."

Mas o que intriga Bene no mais alto grau é a relação que o ator mantém com seu assim-chamado personagem; este aspecto polêmico é constante no trabalho sobre Shakespeare, e ele é frequentemente resolvido em termos de "humores" que acabam por absorver todas as funções da coisa teatral: "Grandes atores, eles se esgotam na busca perpétua do auto-pavor que é reflexo do feminino de autor. Eles endossam e retiram os humores de que são revestidos. Sua ação é o dizer, sua cena, o imaginário. Os figurinos, as armaduras, os objetos de cena decidem os gestos, os movimentos e as vozes, o canto, os risos, os choros, até a afasia do dizer. (...) Macbeth é um crime de palco. A um dado momento, seguindo o roteiro, sua mulher o abandona e, então, adeus!, esta "enfermeira por amor da arte". E no corpo-Macbeth, ao qual até o amor conjugal é negado, restará apenas o trabalho forçado de cada apresentação. Labor desmesuradamente alucinado. Ele passa de uma armadura a outra, cada vez mais pesada, depois é o contorno da cama e da mesa de cabeceira, a mudança de casa atordoante que é a vida. Desmontar as tábuas do palco e revirá-las, braços estendidos no nada, neste 'Amanhã, e amanhã, e ainda outro amanhã/dia após dia rasteja cada amanhã'...”. Até a célebre história da mancha de sangue, que fez, entre outras, a fortuna dessa peça: "História erótico-obscena do ator. Olha. Um braço enfaixado. Uma ferida? Desenrola o curativo, desfaz e desfaz: branco, branco, menos branco, um pouco de vermelho, vermelho, vermelho, mais vermelho (o machucado está aqui?). Desfaz e desenrola ainda, menos vermelho, menos vermelho, menos vermelho Branco, branco, mais branco, mais curativo. Nada. Era o curativo que estava machucado, não o braço. Será isso a melancolia (?)”.

Em um outro texto, a explicitação, mais pessoal, visando menos a razões morais e históricas da peça, aborda outros domínios, mantendo suas resistências quanto ao fundo do projeto anti-cênico: "Eu retiro de cena Macbeth. Já era tempo. O fato é que não se pode fazer ao acaso o projeto de certas operações. Por que? Porque Macbeth é o herói aniquilado por seu próprio projeto. Macbeth não é um espetáculo dentre tantos outros. Somos Macbeth quando desprogramamos nosso cérebro e não podemos programar nossa conversão a zero segundo nosso prazer. Terá sido preciso, ao contrário, atravessar a vida em meio a golpes de espada, então, fazer frente à consciência infeliz, e encontrar Madona Solidão e, enfim, após haver dito adeus a esta senhora, sair de si definitivamente. "Sair de si", é assim que se insulta os loucos. Desde o tempo de minha infância, quando eu buscava o fim do teatro, eis-me, agora, no teatro do fim. Que aprendizagem é desaprender! (...) Macbeth será o fim de todo teatro do possível. (...) A tristeza das coisas que não tiveram jamais um começo desenha sobre o silêncio fechado dos lábios o sorriso dos mortos e, incompreensível, canta a voz da escuta”.

A última das apresentações de Macbeth é um programa cuja severidade explica definitivamente a inexistência de toda relação personalizada, psicológica, filológica ou outra, entre peça, personagem, ator. Haveria somente uma espécie de fisiologia humoral do ator, que é apenas um resto do múltiplo, um momento compósito de automatismos poéticos, no qual só reina triunfalmente o império da voz: "Macbeth marca o fim da escritura cênica e abre o advento da máquina atorial, solicitado pela experiência eletrônica herdada da fase cinematográfica e consolidada na aventura concertista do poema sinfônico (des)dramatizado. (...) Protagonista onívoro é a atorialidade automática do corpo como fisiologia em que a voz sozinha (a diferenciação de 'papéis' é variação fonético-humoral) é sem língua; este interior do corpo é algazarra (salivação, peido, arroto, roncos etc.) amplificados de restos da palavra-som mastigada e vomitada, babada no canto da boca. A afasia de tão grande barulheira oral (...) redobra a apraxia de um corpo, múmia envolta ou recoberta de uma tripla armadura, que tateia cega, em busca de um orgasmo que se esvai, dentre os expedientes do horror (o terror reduzido a um fogo fátuo) e do auto-pavor".

O que resta, então, de Macbeth? Resta-lhe o que resiste, o que persiste, como uma pulsação cardíaca que atormentaria ainda um corpo inanimado, já inorgânico. Em Carmelo Bene, não são mais as vontades em ação que se exprimem, mas sua dimensão ofegante e vazia, tendo como único porvir uma fatigada e penosa revisitação de lugares que sequer pertencem à memória, mas a alguma coisa de profundamente mecânica que resiste em nós. Há mais de Lady Macbeth que de Macbeth, mais de Rei ou de Duncan que de Banquo: cada situação é condensada em seu estado esgotado de puro sopro, como se ela preenchesse lembranças acumuladas que a memória já evacuou, fazendo delas destroços. Tantas condensações - de coexistências, de coerências que fazem fugir toda uma unidade originária da peça, toda distensão do sentido, mas que conseguem recriar em outra parte necessidades físicas e criativas potentes, porque elas ressoam agora diferentemente, em virtualidades diferentes. É nisso que este Macbeth não pertence mais a Shakespeare, mas devém o fato mais específi12 N.T.: No original, "autant en emporte le vent", título francês do filme E $\bigcirc$ Vento Levou. (Gone With The Wind). 
co daquilo que Bene profere, mesmo que nele ressoe ainda a vacuidade de um dizer que nada mais acompanha, nenhuma ação: a cada vez, quase uma paráfrase melancólica de Hamlet - "Palavras, palavras, palavras...".

Recebido em 17/03/2015

Aprovado em 15/06/2015 